\title{
INOVAÇÃO NAS ORGANIZAÇÕES
}

A inovação atingiu nos últimos anos um estatuto peculiar: além de ter ascendido ao Olimpo das buzzwords da gestão, adquiriu um valor positivo em si mesmo. Com efeito, no uso cotidiano, a inovação "é boa", tal como a liderança "é boa", mesmo que a investigação empírica sugira tratar-se de um processo intrinsecamente arriscado e recheado de perigos. A seleção de obras abaixo, elaborada pelo Professor Miguel Pina e Cunha da Universidade Nova de Lisboa, procura proporcionar uma visão integrada e geral do tema. Foram portanto evitadas obras meritórias focadas em uma faceta particular da inovação, por exemplo, em um tipo de inovação - como a de produtos - ou setor - como a inovação no setor automobilístico. A seleção que se segue inclui um clássico absoluto da literatura da gestão (Burns e Stalker), dois livros de fôlego acadêmico, que acolhem uma visão abrangente (Van de Ven et al.; Tidd et al.), um texto orientado para os gestores (Tushman e O'Reilly) e, finalmente, uma obra desafiadora - leia-se "inovadora" - que tem por base os novos desenvolvimentos nas áreas da teoria do caos e da complexidade (Brown e Eisenhardt).

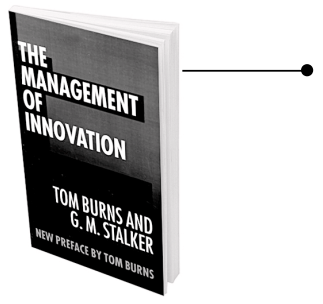

THE MANAGEMENT OF INNOVATION Tom Burns and G.M. Stalker. Oxford : Oxford University Press, 1961. 269 p. Um dos grandes clássicos da teoria das organizações, o livro procura resposta para a forma como se relacionam as organizações e seus respectivos parceiros, nomeadamente o mercado e o ambiente tecnológico. Sua relevância está patente no fato de essa continuar a ser, hoje, uma questão fundamental para a compreensão da dinâmica organizacional. Embora não limitado a ela, o livro apresenta uma contribuição fundamental: a distinção, hoje obrigatória em qualquer programa de gestão, entre estruturas orgânicas - mais fluidas e facilitadoras da inovação - e mecanicistas - mais reguladas e avessas à inovação.

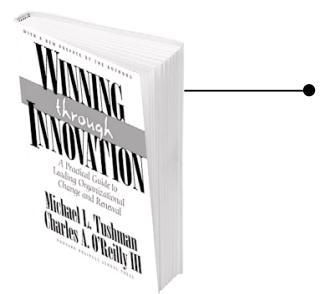

WINNING THROUGH INNOVATION Michael Tushman and Charles A. O'Reilly. Boston : Harvard Business School Press, 1997. 259 p.

Neste livro recheado de exemplos práticos, os autores mostram como a busca do sucesso rápido pode conduzir a dificuldades no longo prazo. Tushman e O'Reilly defendem que o sucesso continuado depende da capacidade de gerir a inovação e a mudança de um modo complexo, capaz de combinar as facetas radical e incremental. É no entendimento dessa dualidade e na capacidade de sintetizar estabilidade e mudança que se esconde a semente do sucesso.

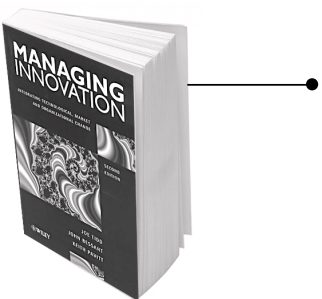

MANAGING INNOVATION: integrating technological, market and organizational change Joe Tidd, John Bessant and Keith Pavitt. Chichester : Wiley, 2001.388 p.

Uma das dificuldades com as quais se confronta o recém-chegado ao campo da inovação é a de desbravar um terreno multidisciplinar e abordado a partir de vários níveis de análise, do comportamento individual aos contextos nacionais. Neste livro, três acadêmicos britânicos, Tidd, Bessant e Pavitt, fornecem um quadro integrativo, no qual são combinadas as perspectivas organizacional, tecnológica e de mercado.

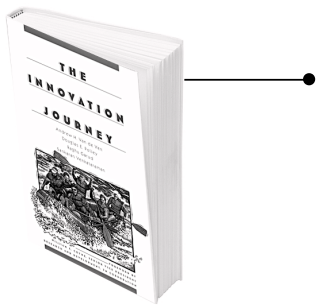

THE INNOVATION JOURNEY Andrew H. Van de Ven, Douglas E. Polley, Raghu Garud and Sankaran Venkataraman, New York : Oxford University Press. 422 p.

Uma exposição profunda dos resultados do Minnesota Innovation Research Program, um projeto longitudinal envolvendo 30 investigadores que acompanharam o desenvolvimento em campo de 14 processos de inovação. Os resultados constituem um importante desafio à literatura dominante, desmistificando o caráter linear, seqüencial, planejado, do processo de inovação. O que daqui emerge é um processo caracterizado pelos autores como um sistema dinâmico não linear.

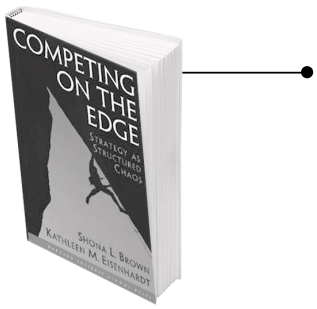

COMPETING ON THE EDGE: strategy as a structured chaos Shona Brown and Kathleen Eisenhardt. Boston : Harvard Business School Press, 1998. 320 p.

Embora o termo não surja sequer no índice remissivo, este pode ser lido como um livro sobre inovação. Baseando-se na teoria do caos e da complexidade, as autoras introduzem um conjunto de idéias insuficientemente exploradas na literatura das organizações e da gestão: a importância dos tempos e ritmos - internos e externos -, da capacidade de improvisação e daquilo que designaram como semi-estruturas, isto é, estruturas que combinam, na justa medida, elementos orgânicos e mecanicistas. Uma espécie de releitura do modelo de Burns e Stalker, visto a partir de Palo Alto e na perspectiva das indústrias de alta velocidade. 